\title{
Epigenetic Regulation during Fetal Femur Development: DNA Methylation Matters
}

\author{
María C. de Andrés ${ }^{1,2,3}$, Emmajayne Kingham ${ }^{1,2}$, Kei Imagawa ${ }^{1,2,4}$, Antonio Gonzalez ${ }^{3}$, \\ Helmtrud I. Roach ${ }^{1,2 \dagger}$, David I. Wilson ${ }^{2}$, Richard O. C. Oreffo ${ }^{1,2,5 *}$
}

1 Bone and Joint Research Group, University of Southampton, Southampton, United Kingdom, 2 Centre for Human Development, Stem Cells and Regeneration Human Development and Health, Institute of Developmental Sciences, University of Southampton, Southampton, United Kingdom, 3 Instituto de Investigación Sanitaria-Hospital Clínico Universitario de Santiago, Santiago de Compostela, Spain, 4 Tohoku University School of Medicine, Sendai, Japan, 5 Stem Cell Unit, Department of Anatomy, College of Medicine, King Saud University, Riyadh, Kingdom of Saudi Arabia

\begin{abstract}
Epigenetic modifications are heritable changes in gene expression without changes in DNA sequence. DNA methylation has been implicated in the control of several cellular processes including differentiation, gene regulation, development, genomic imprinting and X-chromosome inactivation. Methylated cytosine residues at CpG dinucleotides are commonly associated with gene repression; conversely, strategic loss of methylation during development could lead to activation of lineage-specific genes. Evidence is emerging that bone development and growth are programmed; although, interestingly, bone is constantly remodelled throughout life. Using human embryonic stem cells, human fetal bone cells (HFBCs), adult chondrocytes and STRO $-1^{+}$marrow stromal cells from human bone marrow, we have examined a spectrum of developmental stages of femur development and the role of DNA methylation therein. Using pyrosequencing methodology we analysed the status of methylation of genes implicated in bone biology; furthermore, we correlated these methylation levels with gene expression levels using qRT-PCR and protein distribution during fetal development evaluated using immunohistochemistry. We found that during fetal femur development DNA methylation inversely correlates with expression of genes including iNOS (NOS2) and COL9A1, but not catabolic genes including MMP13 and IL1B. Furthermore, significant demethylation was evident in the osteocalcin promoter between the fetal and adult developmental stages. Increased TET1 expression and decreased expression of DNA (cytosine-5-)-methyltransferase 1 (DNMT1) in adult chondrocytes compared to HFBCs could contribute to the loss of methylation observed during fetal development. HFBC multipotency confirms these cells to be an ideal developmental system for investigation of DNA methylation regulation. In conclusion, these findings demonstrate the role of epigenetic regulation, specifically DNA methylation, in bone development, informing and opening new possibilities in development of strategies for bone repair/tissue engineering.
\end{abstract}

Citation: de Andrés MC, Kingham E, Imagawa K, Gonzalez A, Roach HI, et al. (2013) Epigenetic Regulation during Fetal Femur Development: DNA Methylation Matters. PLoS ONE 8(1): e54957. doi:10.1371/journal.pone.0054957

Editor: Nuno M. Neves, University of Minho, Portugal

Received July 23, 2012; Accepted December 18, 2012; Published January 28, 2013

Copyright: (C) 2013 de Andrés et al. This is an open-access article distributed under the terms of the Creative Commons Attribution License, which permits unrestricted use, distribution, and reproduction in any medium, provided the original author and source are credited.

Funding: Grant support from Wessex Medical Research (M19; HIR and RO) and BBSRC G006970/1 (RO). MCA was supported by Programa Sara Borrell, Instituto de Salud Carlos III, Spain. Recruitment for fetal tissues was supported by funding from Comprehensive Local Research Network (National Institute for Health Research Clinical Research Network). The funders had no role in study design, data collection and analysis, decision to publish, or preparation of the manuscript.

Competing Interests: The authors have declared that no competing interest exist.

*E-mail: roco@soton.ac.uk

$\dagger$ Deceased.

\section{Introduction}

Epigenetic regulation of gene expression is an important mechanism implicated in cell stemness, differentiation and function. Epigenetic modifications are heritable changes in gene expression that are not encoded by the DNA sequence. Methylated cytosine residues at $\mathrm{CpG}$ dinucleotides are commonly associated with gene repression [1]. In prokaryotes, the major role of DNA methylation is to protect host DNA against degradation by restriction enzymes. In contrast, eukaryote DNA methylation has been implicated in the control of several cellular processes including differentiation, gene regulation, development, genomic imprinting, X-chromosome inactivation and suppression of repetitive element transcription and transposition $[2,3,4]$.

Current research has focused on the role of epigenetic processes in fetal programming and the potential consequences, including enhanced susceptibility, to chronic diseases in adulthood $[5,6]$.
Strategic loss of methyl groups during development could lead to activation of specific genes in the appropriate lineage [7]. In addition, some of the up-regulated genes are normally exclusively expressed in terminally differentiated cells [8]. These findings raise the possibility that DNA methylation contributes to silencing of tissue-specific genes in non-expressing cells, confirming DNA methylation to be a global repressor of gene expression [7].

The methylation status of DNA domains appears to be faithfully propagated during development [9]. The DNA methylation maintenance enzyme DNA methyltransferase 1 (DNMT1) is partly responsible for this stability, but there is likely to be another, as yet unknown, component that regulates this process [7]. Furthermore, inhibition of DNMT1 results in reduced methylation and activation of target genes.

In contrast, in primordial germ cells, the genome undergoes extensive demethylation, including the removal of previous parent- 
specific methylation marks regulated by imprinted gene expression [3]. New imprints occur during gametogenesis, in a parent-oforigin-specific manner. Within a few days of fertilization, genomewide demethylation occurs followed by a wave of de novo methylation, both of which are resisted by imprinted loci [10]. Subsequently DNA methylation patterns must then be maintained during the phase of rapid cellular proliferation in fetal and postnatal development.

Here we provide evidence for epigenetic regulation during fetal femur development. Human fetal femurs of the age used in this study contain predominantly epiphyseal chondrocytes surrounded by a perichondrium/periosteum of an outer fibroblastic layer and, an inner mesenchymal stem cell layer with osteogenic, chondrogenic and adipogenic differentiation potential as published by Mirmalek-Sani and coworkers [11]. Such multipotency confirms human fetal bone cells (HFBCs) to be an ideal developmental system for investigation of DNA methylation regulation. In order to explore a potential link between DNA methylation changes in gene expression observed during fetal development, we have selected genes that we have previously reported to be associated with osteoarthritis $(\mathrm{OA})[12,13,14]$. Using human embryonic stem cells (hESCs), HFBCs, adult chondrocytes and a STRO- ${ }^{+}$skeletal stem cell containing population of adult bone marrow, we have examined a spectrum of developmental stages of femur development.

\section{Materials and Methods}

\section{Fetal Sample Procurement}

Human fetal femurs were obtained after termination of pregnancy according to guidelines issued by the Polkinghome Report and with ethical approval from the Southampton \& South West Hampshire Local Research Ethics Committee. Fetal age was determined by measuring fetal foot length and expressed in weeks post conception (WPC). In total 12 samples were used (cultured and uncultured) with a mean age of $8.3 \pm 1.0$ WPC. Skeletal muscle surrounding the femur was removed in sterile phosphatebuffered saline (PBS) prior to femur dissection and digestion with collagenase B overnight. The cell suspension was filtered $(70 \mu \mathrm{m}$ filter) and collected cells were either directly lysed for nucleic acid isolation or cultured on tissue culture plastic in $\alpha$-MEM containing $10 \%$ FCS.

\section{Cartilage Procurement and Chondrocyte Isolation}

Adult femoral heads were obtained with informed patient consent and the permission of the Local Ethics Committee following joint replacement surgery due to OA $(n=13$, age $71.6 \pm 8.2$ years; $3-5$ OARSI score) or due to fracture of the neck of femur (normal) ( $\mathrm{n}=15$, age $76.8 \pm 16.5$ years) (used as a non-OA control) [15]. Cartilage was dissected within 6 hours of surgery and chondrocytes from the surface layer of OA femoral heads or the deep zone of normal cartilage were isolated, as in previous studies [15]. The cartilage was cut into small pieces and digested by sequential treatment with $10 \%$ trypsin in PBS for 30 minutes; $1 \mathrm{mg} / \mathrm{ml}$ of hyaluronidase in PBS for 15 minutes and finally collagenase B in DMEM/F12 for $12-15$ hours at $37^{\circ} \mathrm{C}$.

\section{Bone Marrow Procurement and $\mathrm{STRO}^{+}$Isolation}

Bone marrow was obtained with informed patient consent and the permission of the Local Ethics Committee following joint replacement surgery. Marrow cells were isolated from trabecular bone by suspending in $\alpha$-MEM. The $\mathrm{STRO}^{+}$fraction, reported to contain the skeletal/mesenchymal stem cell population and osteoprogenitor cells $[16,17]$, was isolated by magnetic activated cell sorting as previously described [18] using STRO-1 antibody hybridoma supernatant (hybridoma cell line was a kind gift from Dr J Beresford, University of Bath). The $\mathrm{STRO}^{+}$and $\mathrm{STRO}^{-}$ fractions were collected and RNA/DNA isolated immediately (uncultured) or incubated on tissue culture plastic in basal media $(10 \% \mathrm{FBS}, \alpha-\mathrm{MEM})$ at $37^{\circ} \mathrm{C}$ in a humidified incubator, $5 \% \mathrm{CO}_{2}$.

\section{Human Embryonic Stem Cell Culture}

Hues-7 human embryonic stem cells (hESCs) (D. Melton, Howard Hughes Medical Institute/Harvard University) were initially cultured on $\gamma$-irradiated mouse embryonic fibroblasts (MEFs) in Knockout DMEM (Invitrogen) supplemented with 10\% knockout serum replacement (Invitrogen), $1 \mathrm{mM}$ L-glutamine (Invitrogen), $50 \mu \mathrm{M} \beta$-mercaptoethanol (Sigma), $0.1 \mathrm{mM}$ nonessential amino acids (Invitrogen), $10 \mathrm{ng} / \mathrm{ml}$ basic FGF (Peprotech Ltd, London, UK) and $100 \mu \mathrm{g} / \mathrm{ml}$ penicillin/streptomycin (Invitrogen). Subsequent maintenance of hESGs on matrigel coated (BD Biosciences) tissue culture plastic with 24 hours MEFconditioned medium (C.M.) followed. Throughout, hESCis were incubated at $37^{\circ} \mathrm{C}$ in atmospheric $(\sim 20 \%)$ oxygen. RNA and DNA were isolated from hESCs following a minimum of 3 passages on matrigel coated tissue culture plastic.

\section{DNA and RNA Extraction}

Total RNA and genomic DNA were isolated simultaneously using Qiagen AllPrep DNA/RNA Mini Kit according to the manufacturer's instructions. RNA was reverse-transcribed with avian myeloblastosis virus reverse transcriptase, oligo $(\mathrm{dT})_{15}$ and random primers [19].

\section{Quantitative Reverse Transcription-polymerase Chain Reaction (qRT-PCR)}

qRT-PCR was conducted using Power SYBR Green PCR Master Mix (Applied Biosystems) and ABI Prism 7500 detection system (Applied Biosystems). Exon-exon boundary primers were designed with Primer Express 3.0 software (Applied Biosystems) with the exception of IL1B, which was designed by and purchased from PrimerDesign Ltd, Southampton, UK. Primer sequences used were iNOS GAGGAGCAGGTCGAGGACTAT (F), TCTTCGCGTGGTAAGGAAATAG (R); COL9Al CGTGGTGCTCTTGGTTTGA (F), CACGCTCGCGCTTTTCTC (R); MMP13 TTAAGGAGCATGGGGACTTCT (F), CACAGGAGGAAAAGCATGAG (R); IL1B TGGCAATGAGGATGACTTGTTC (F), CTGTAGTGGTGGTCGGAGATT (R); osteocalcin GGCAGGGAGGTAGTGAAGAG (F), CTCACACACCTCCCTCCT (R); DNMT1 CAGGCCGAATGAGACTGACA (F), GTGGGTGTTCTCAGGCCTGTAG (R) and GAPDH CAAGGTGGTCTCGTGTGACTTC (F), TCATACGAGGAAATGAGCTTGACA (R). Samples were run in triplicate, $\mathrm{Ct}$ values were analysed using the $2^{-\Delta \Delta \mathrm{Ct}}$ method and the expression of target genes were normalised to GAPDH house keeping gene expression.

\section{Analysis of DNA Methylation by Pyrosequencing}

$500 \mathrm{ng}$ genomic DNA was bisulfite treated using EZ DNA Methylation-Gold ${ }^{\mathrm{TM}}$ Kit (Zymo Research Corporation) according to the manufacturer's instructions. Promoter regions of interest were amplified using Platinum ${ }^{\circledR}$ PCR Normal Supermix or High Fidelity (Invitrogen) and purity confirmed by agarose gel electrophoresis. Percentage DNA methylation in the promoter regions was quantified using pyrosequencing primers designed with Pyrosequencing $^{\mathrm{TM}}$ Assay Design Software Ver 2.0 (Qiagen) 

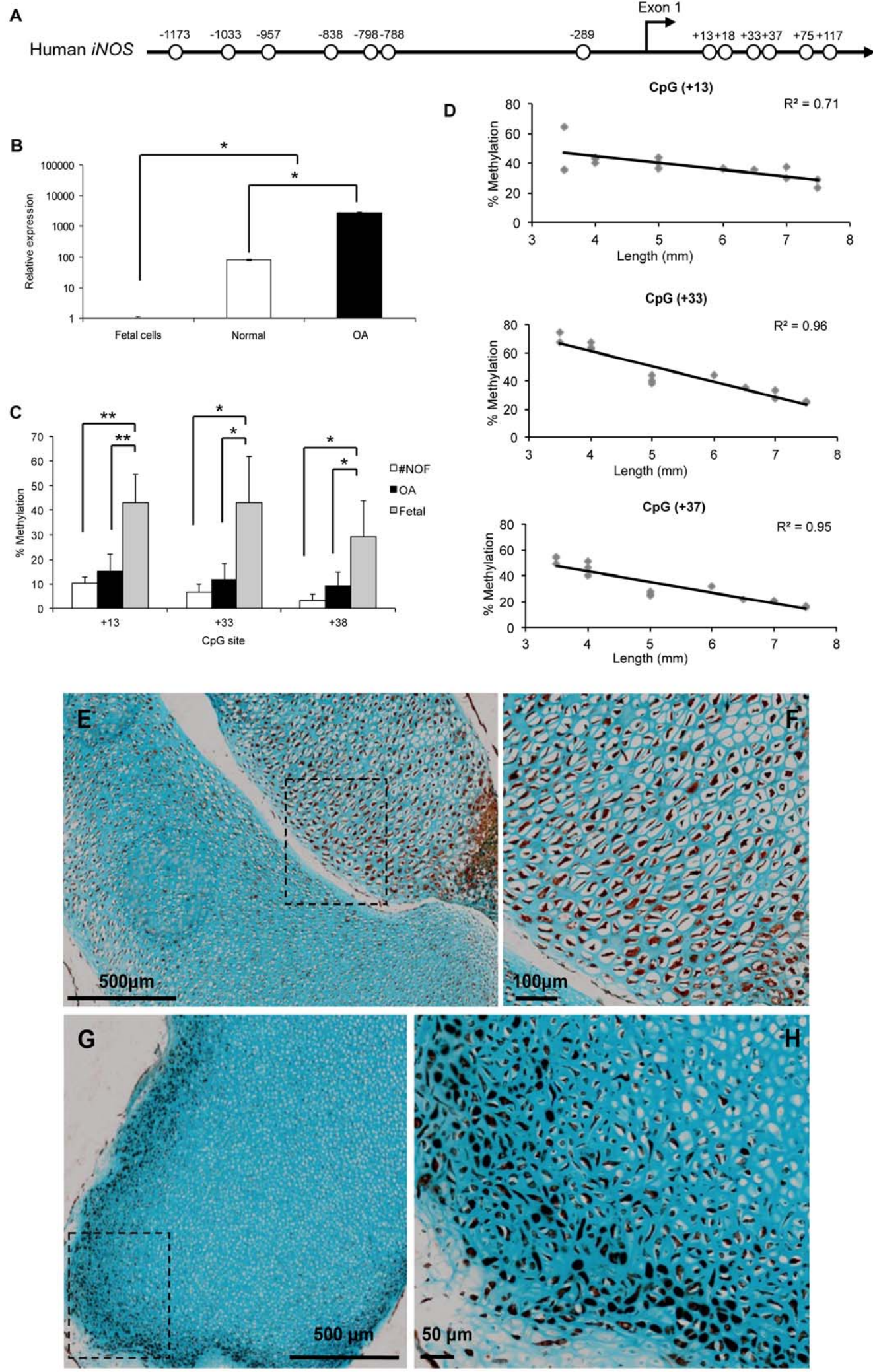

Figure 1. iNOS epigenetic regulation during fetal femur development. A. Human iNOS proximal promoter, each circle represents a $\mathrm{CpG}$ site. B. Relative expression of $i N O S$ in HFBCs cells and adult chondrocytes from healthy and OA patients. C. Methylation status of $\mathrm{CpG}$ sites localised at the transcription start site of iNOS gene in HFBCs and adult chondrocytes. D. Correlation between foot length and CpG sites methylation level. E. Localization of iNOS in a fetal bone from a $4.5 \mathrm{~mm}$ fetal sample. See a higher magnification of the square in F. G. Immunohistochemical localization of iNOS in a fetal bone from an $8.5 \mathrm{~mm}$ fetal sample. See a higher magnification of the square in $\mathbf{H}$. doi:10.1371/journal.pone.0054957.g001 

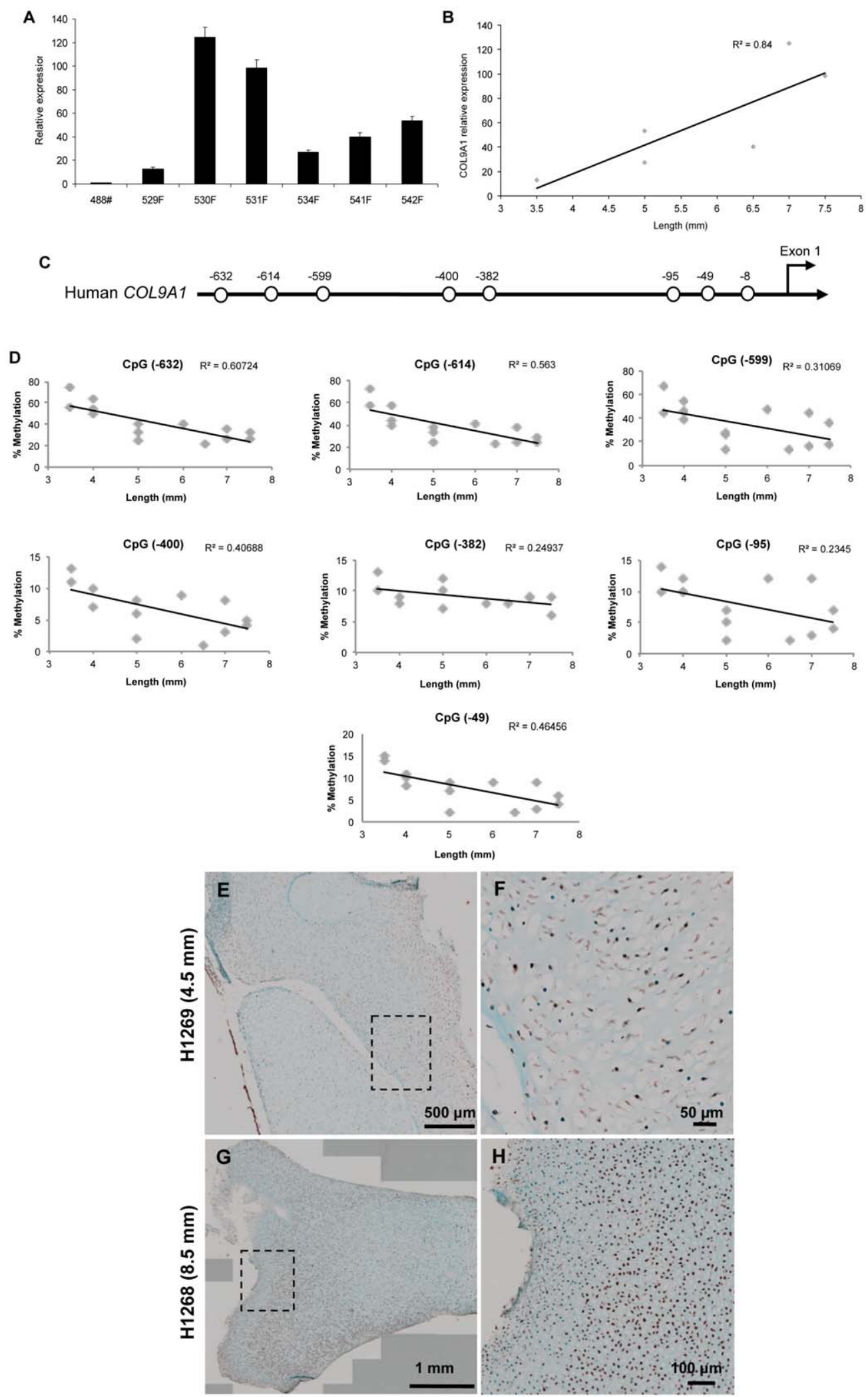

Figure 2. COL9A 1 regulation during fetal femur development. A. Relative expression of COL9A1 in different HFBCs samples. B. Correlation between foot length and COL9A1 relative expression. C. Human COL9A1 proximal promoter, each circle represents a CpG site. $\mathbf{D}$. Correlation between foot length and the percentage of methylation of all the CpG sites localised at the proximal promoter. E. Immunohistochemical localisation of COL9A1 in a fetal bone from a $4.5 \mathrm{~mm}$ fetal sample. See higher magnification in F. G. Localisation of COL9A1 in a fetal bone from an $8.5 \mathrm{~mm}$ fetal sample. See a higher magnification of the square in $\mathbf{H}$. doi:10.1371/journal.pone.0054957.g002 
A

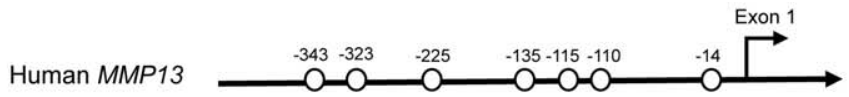

B

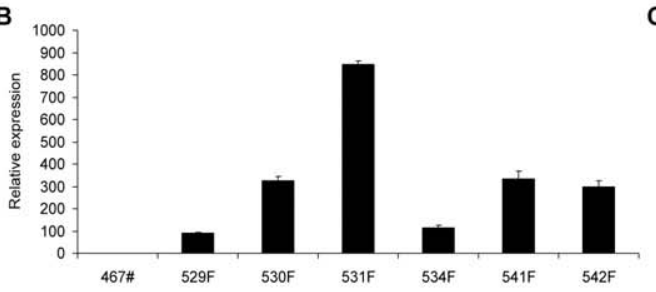

C

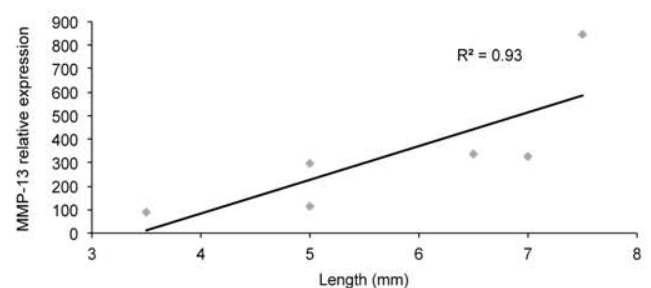

D

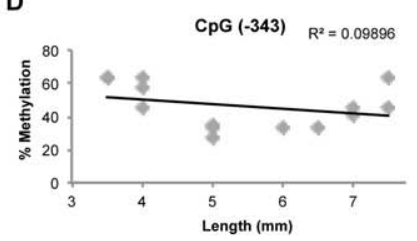

CpG (-135)
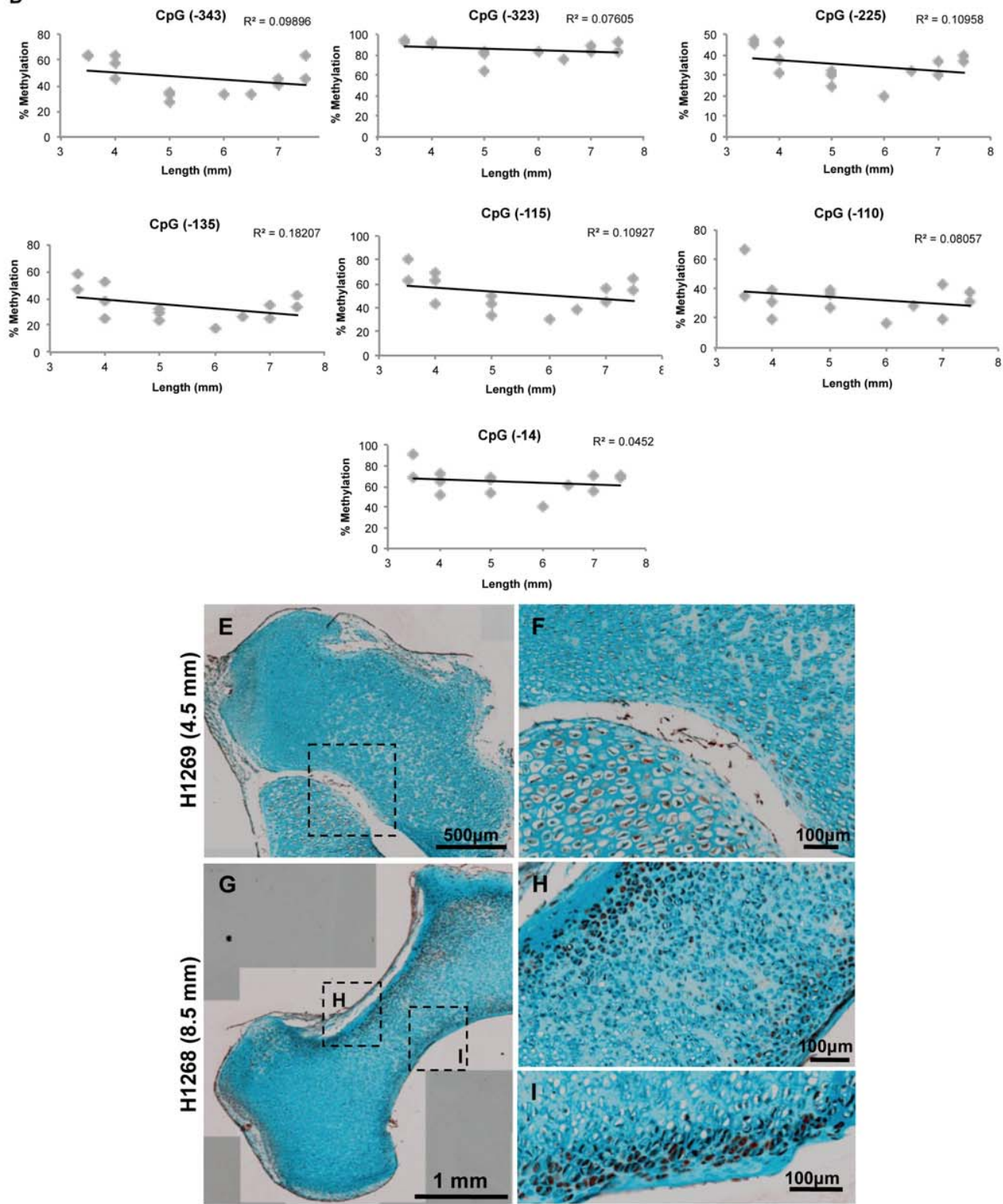

Figure 3. Changes in MMP13 expression during fetal femur development. A. Human MMP13 proximal promoter, each circle represents a CpG site. B. Relative expression of MMP13 in different HFBCs samples. C. Correlation between sample age and MMP13 relative expression. D. Correlation between foot length and the percentage of methylation of all the CpG sites localised at the proximal promoter. E. Immunohistochemical localisation of MMP13 in a fetal bone from a $4.5 \mathrm{~mm}$ fetal sample. See higher magnification in F. G. Localisation of MMP13 in a fetal bone from an $8.5 \mathrm{~mm}$ fetal sample. See a higher magnification of the squares in $\mathbf{H}$ and $\mathbf{I}$.

doi:10.1371/journal.pone.0054957.g003 
A

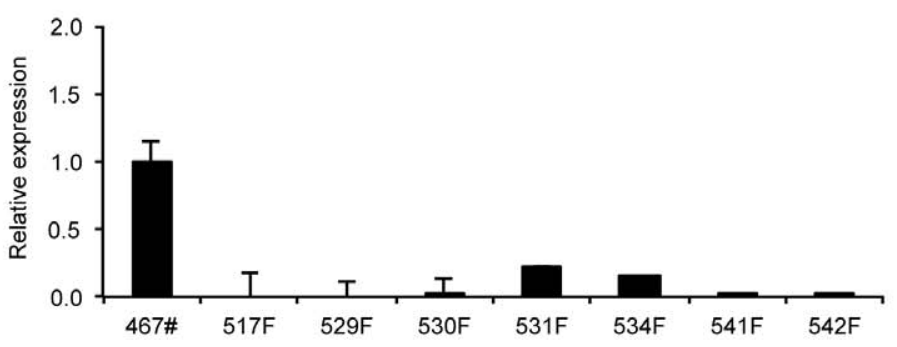

B

Human $I L-1 \beta$
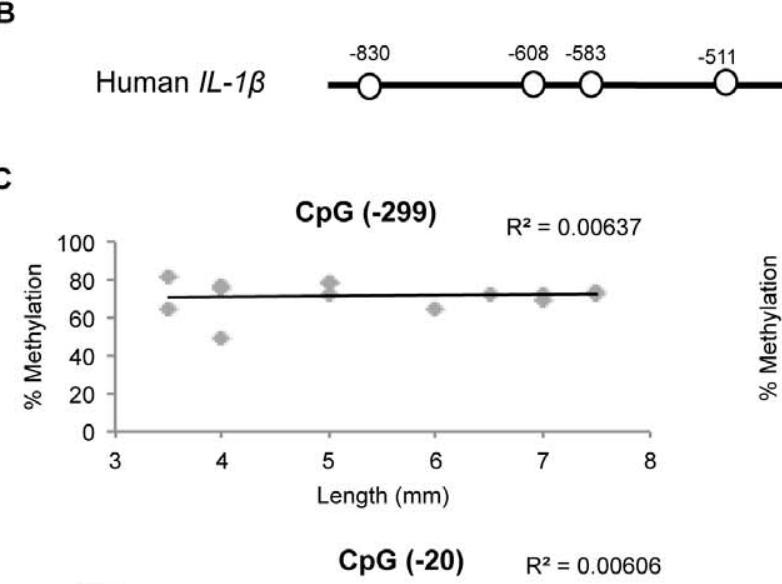

C
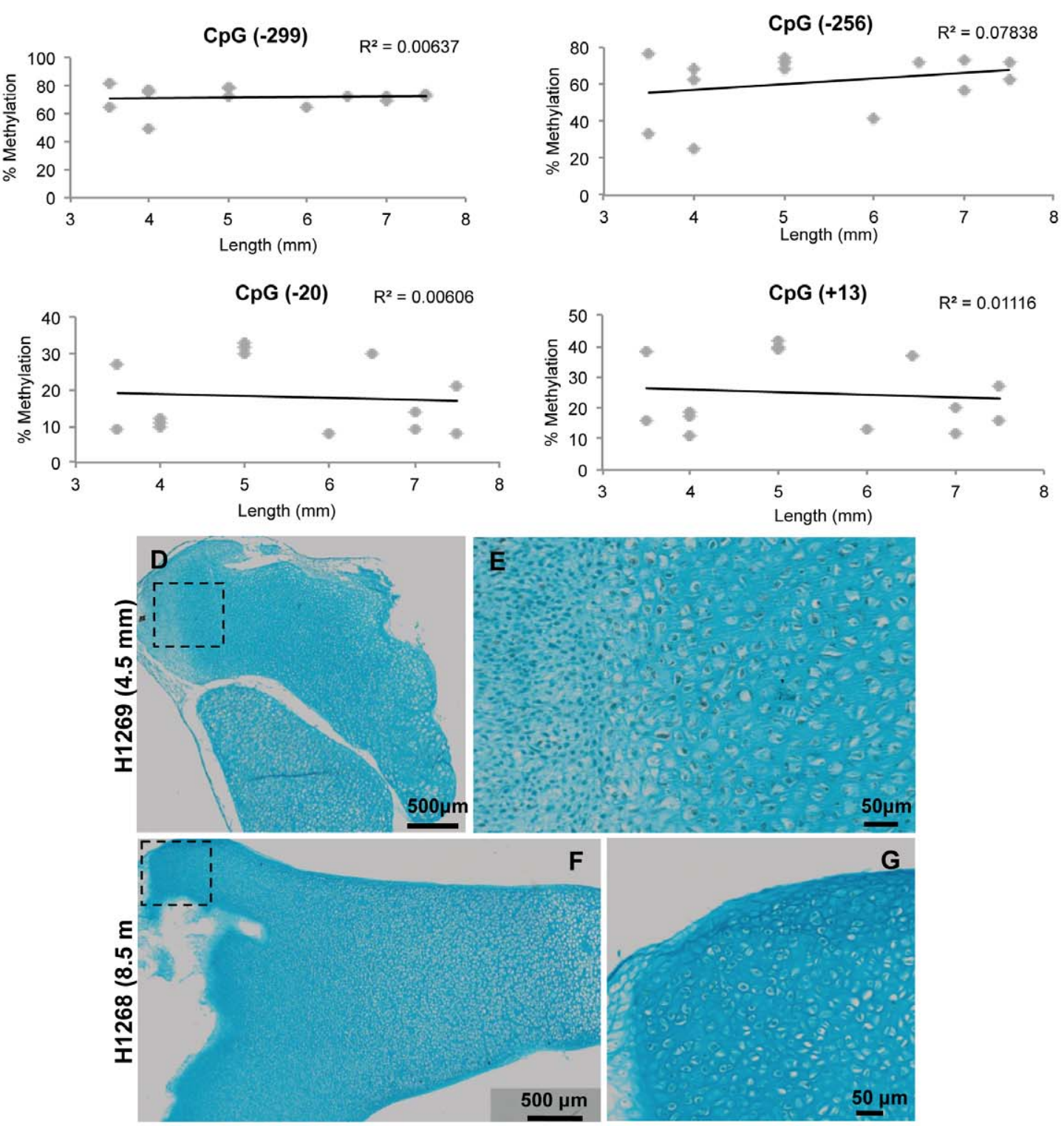

Figure 4. Absence of considerable changes in $I L 1 B$ during fetal femur development. A. Relative expression of $I L 1 B$ in different $H F B C s$ samples compared to healthy chondrocytes. B. Human IL $1 B$ proximal promoter, each circle represents a $\mathrm{CpG}$ site. C. Correlation between foot length and the percentage of methylation of all the CpG sites localised at the proximal promoter. D. Localisation of IL $1 \mathrm{~B}$ in a fetal bone from a $4.5 \mathrm{~mm}$ fetal sample. See higher magnification in E. F. Immunohistochemical localisation of IL1B in a fetal bone from an $8.5 \mathrm{~mm}$ fetal sample. See a higher magnification of the square in $\mathbf{G}$. doi:10.1371/journal.pone.0054957.g004 


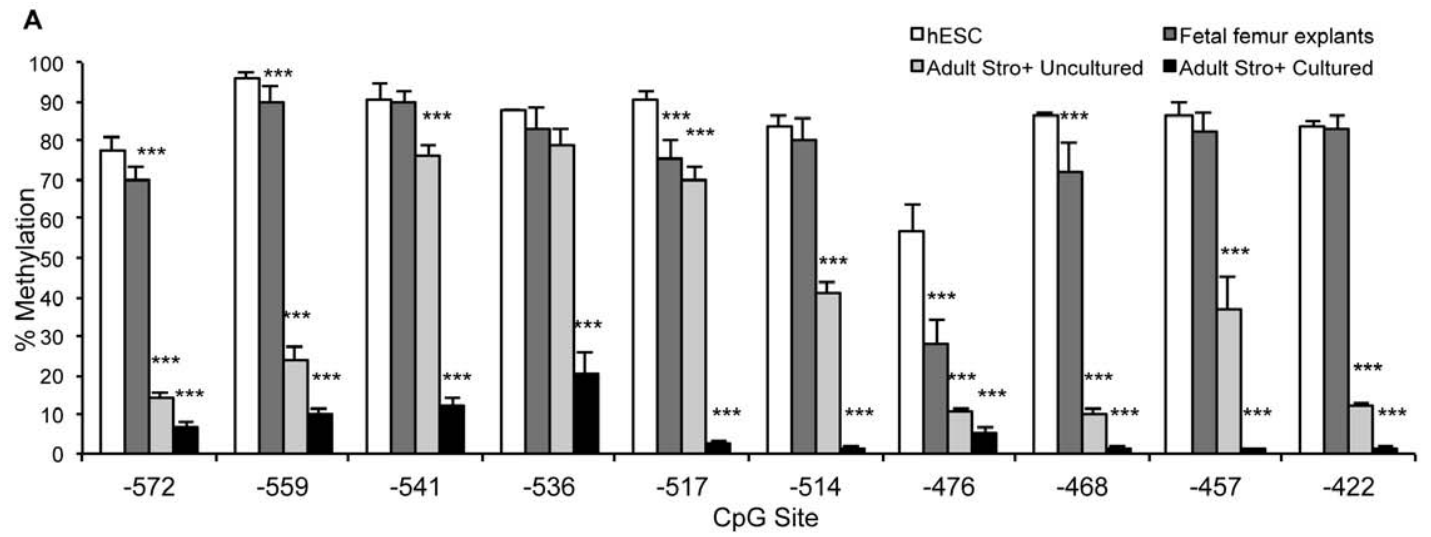

B
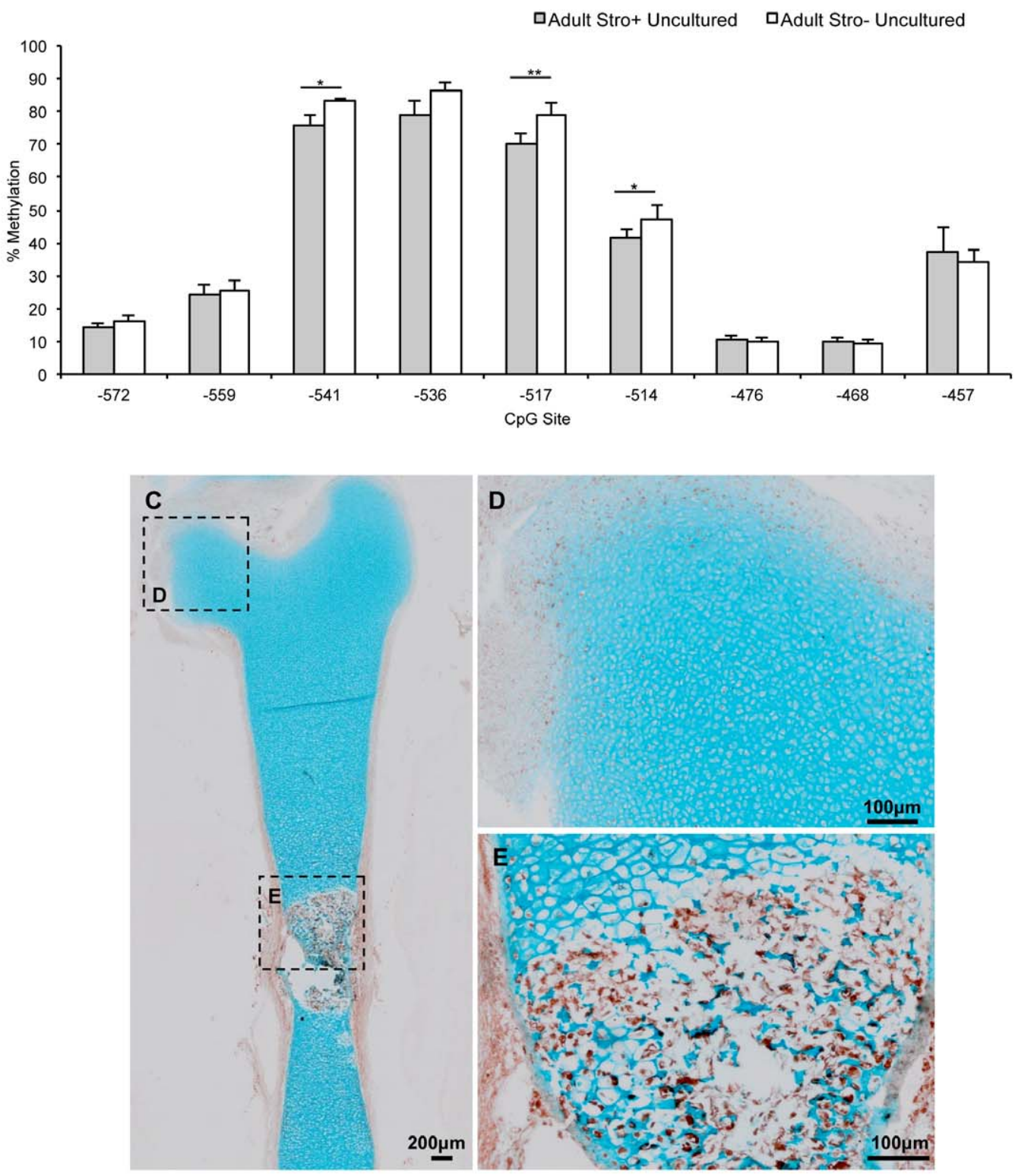

Figure 5. Changes in the methylation status of osteocalcin during fetal femur cell development. A. Osteocalcin promoter methylation status in embryonic, fetal and adult cells. B. Osteocalcin promoter methylation status in STRO-1+ (skeletal stem cell containing) and STRO-1 ${ }^{-}$fractions of adult bone-marrow cells. C. Localisation of STRO-1 in a fetal bone from a $6 \mathrm{~mm}$ fetal sample. See higher magnification in D-E. doi:10.1371/journal.pone.0054957.g005 


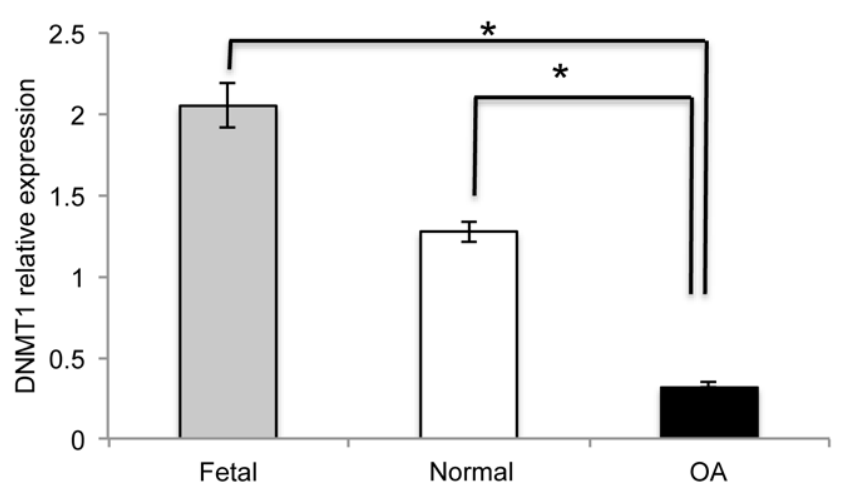

Figure 6. Changes in DNMT1 expression in HFBCs and adult chondrocytes. Relative expression of DNMT1 during chondrocyte evolution. Levels of DNMT1 were measured by qRT-PCR. doi:10.1371/journal.pone.0054957.g006

and PyroMark ${ }^{\mathrm{TM}} \mathrm{MD}$ (Qiagen) according to the manufacturer's instructions. Primer sequences used were iNOS TTGGATGGTATGGGGTGAGTATAAAT (F), CGAATCGCCTCATCAAAAATAACG (R), TTTTAAAACAAAAATAAAACTAAATTCTCT (Seq); COL9A1_1 GTTGTTGTGAGAATTAAATGGTATTAAG (F), ACACGCAAGAATCATTATTTATCA (R), CGCAACAATCATTATTTATC (Seq); COL9A1_2 AGGGATTGAAATTTAGGTTGAT
(F), AAATTCGAATAAAAATATACCGACTAA (R), GGATTGAAATTTAGGTTGAT (Seq); COL9A1_3 TGAGGGTTAAAAGTAAAGGGAGAG (F), TTTCCGCTATAAATCGCTCCTT (R), GGGAGAGAATTAGAGGTATT (Seq); MMP13_1 AATTAGTATTAAGTTTTTTTTTATGGAAGT (F), TTCAACAAAATCTCAAAACGCATCTAA (R), AАATTTTTTTTTTTTTACGTTCTAT (Seql), GTCAAAACGCATCTAAC (Seq2); MMP13_2 ATGGGTTTTGAGATTTTG (F), ACCCGTAAATACATCTTAAATA (R), CAATCACTTAAAAATAAACATAGTT (Seq1), AATAATACGTAAAAACTATTATG (Seq2); IL1B_1 ATGGAAGGGTAAGGAGTAGTAA (F), CCGACATATAGTAAATTTAAAGATTGTT (R), ATACTAAATTTAAACATTCTTCTA (Seq); IL1B_2 ATGAAGATTGGTTGAAGAGAATTTTAGA (F), ATTTCTCAACGTCGTACTTCTAGTTTTAA (R), ATTTTAGAGTAGTTTGTTGTG (Seq); Osteocalcin_1 AGTAGGTTGTTTTTGGTGATTTAT (F), CGAACTATGTCACAACGTATAATTTG (R), GGTTGTTTTTGGTGATTTA (Seq); Osteocalcin_2 AGGTAGTTTGTTGTGGGTGTAGTT (F), CGCGACGTCGATTAACTTTAA (R), GTTTGTTGTGGGTGTAGT (Seq).

\section{Immunohistochemistry}

Whole femurs were fixed in 95\% ethanol, embedded in paraffin wax and sectioned at $6 \mu \mathrm{m}$. Permeabilisation with $0.1 \%$ Triton X100 and pronase enzymatic digestion for COL9A1 were employed. Endogenous peroxidase activity was quenched with

A

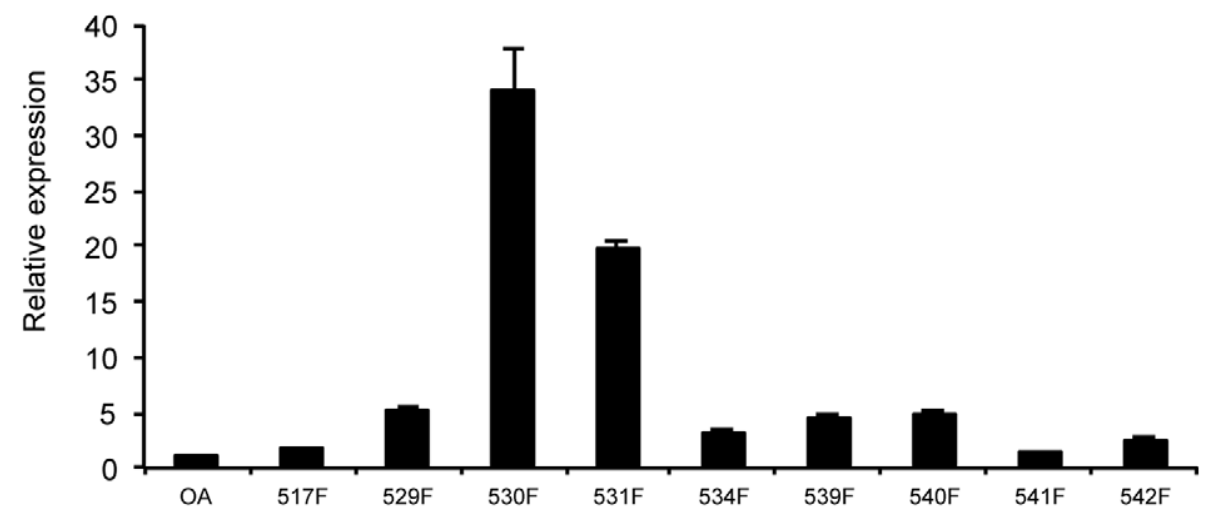

B

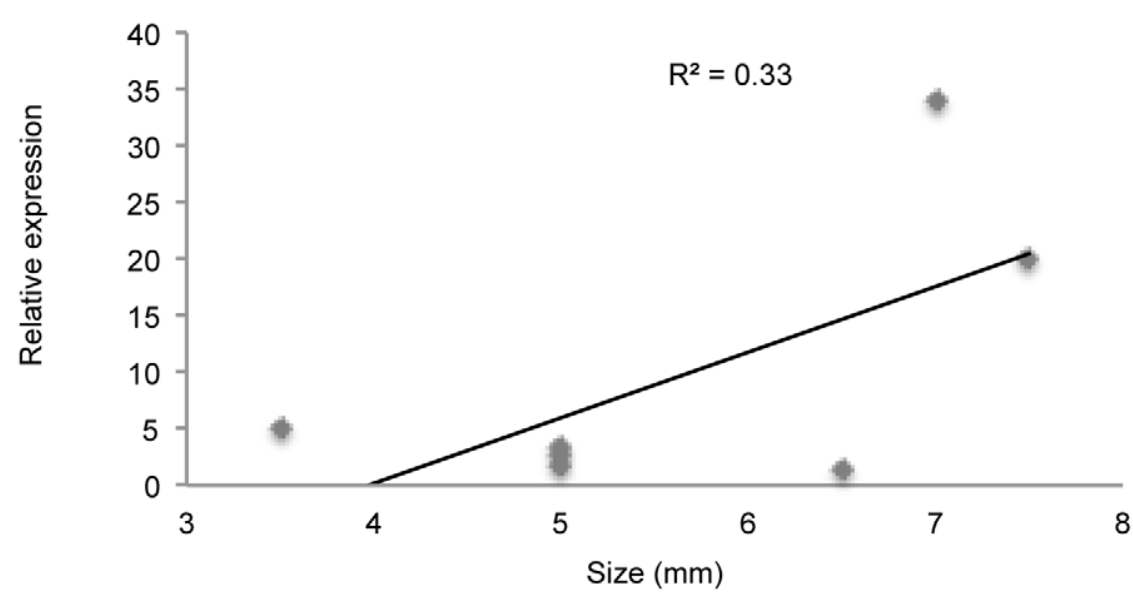

Figure 7. Relative expression of TET1 in HFBCs cells. A. Levels of TET1 were measured by qRT-PCR in comparison with healthy chondrocytes. B. Correlation of TET1 with sample age. doi:10.1371/journal.pone.0054957.g007 
$3 \% \mathrm{H}_{2} \mathrm{O}_{2}$, sections were blocked with $1 \%$ bovine serum albumin (BSA) in PBS and incubated overnight at $4^{\circ} \mathrm{C}$ with primary antibody in 1\% BSA (iNOS (BML-SA200, Enzo Life Sciences, Inc., PA), COL9A1 (ab75807, Abcam, UK), MMP13 (ab39012, Abcam, UK), IL1B (AF-201-NA, R\&D Systems, Inc., MN) and STRO-1 (hybridoma supernatant, Dr J Beresford, University of Bath). Sections were washed with PBS and incubated for 1 hour with biotinylated secondary antibody. Avidin-biotin method linked to peroxidase and 3-amino-9-ethylcarbazole (AEG) and counterstaining with $1 \%$ alcian blue was used to visualize, positive staining appears reddish-brown. Appropriate isotype and secondary antibody only controls were used to confirm specific staining. Virtual digital slides were acquired using a dotSlide system (Olympus) and analysed with OlyVIA software (2.4).

\section{Statistical Analysis}

Data is expressed as the mean $\pm \mathrm{SD}$. Statistical analysis was performed using SPSS software, version 17.0 (SPSS, Chicago, IL) where Mann-Whitney 2-tailed $\mathrm{U}$ test was used to compare between groups or ANOVA where it was necessary, and Spearman's rank correlation coefficient was used for correlation studies. $P$ values less than 0.05 were considered significant.

\section{Results}

\section{iNOS Gene Expression Correlates with Loss of Methylation during Fetal Femur Development}

The human iNOS promoter (sparse CpG promoter) has 7 CpG sites within the 1,400-bp sequence upstream of exon 1 and 6 CpG sites within the exon 1 (GenBank accession No. AF017634) (Figure 1A); the transcription start site was located $30 \mathrm{bp}$ downstream of a TATA box [20]. In activated chondrocytes, iNOS expression is known to be significantly higher than in healthy chondrocytes [21]. However, a significant increase in iNOS expression from HFBCs to adult healthy chondrocytes was observed (Figure 1B). This significant increase correlated with a significant loss of methylation of $\mathrm{CpG}$ sites localized near the transcription start site of $i N O S$ gene. The CpG sites in the initiation region of the first exon $(+13,+33$ and +37$)$, were largely unmethylated in normal and OA patients but, critically, increased methylation was observed in HFBCs (Figure 1C). Furthermore, the degree of methylation was inversely correlated to foot length and, thus, to the age of the sample (CpG sites $+13,+33$ and +37 mean $\mathrm{R}=0.87$ ) (Figure 1D). However, immunohistochemical analysis demonstrates that the majority of cells from fetal femurs produce iNOS (Figure 1E-H). Although iNOS distribution was observed to change with the age of the sample; in tissue samples from 7-8 WPG fetus $(\mathrm{n}=8)$, iNOS displayed a tissue wide distribution (Figure 1E-F). However, in samples from 8.5-9 WPC fetus $(n=6)$, iNOS staining was enhanced with localisation limited to the superficial area (Figure 1G-H).

\section{COL9A1 Gene Expression Correlates with Loss of Methylation during Fetal Femur Development}

High levels of COL9A1 expression were found in all the HFBCs

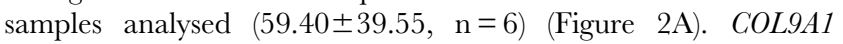
expression levels were significantly correlated with fetal foot length $(\mathrm{R}=0.84)$ (Figure 2B).

The human COL9A1 promoter (sparse CpG promoter) contains $8 \mathrm{CpG}$ sites in the 1,000-bp sequence upstream of exon 1 (GenBank accession No. AF036110), relative to the transcriptional start site $(+1)$ [22] (Figure 2C). In general, methylation levels in all CpG sites in the COL9A1 promoter region were inversely correlated with foot length and developmental age; i.e. the oldest fetal sample analysed displayed the lowest percentage of CpG site methylation (Figure 2D).

Immunohistochemical analysis showed that the majority of cells from fetal femurs stained positively for COL9A1 (Figure 2E-H). Indeed, COL9Al distribution was observed to change with the age of the sample; in tissue samples from 7-8 WPG fetus, COL9A1 staining was weak with widespread distribution throughout the tissue (Figure 2E-F). In contrast, in older samples from 8.5-9 WPC fetus, COL9A1 staining was considerably stronger and was typically localised to the proximal and distal heads (Figure 2G-H) of the fetal femur.

\section{MMP13 Gene Expression does not Correlate with Loss of Methylation during Fetal Femur Development}

The human MMP13 promoter (sparse CpG promoter) has 7 CpG sites in the 400-bp sequence upstream of exon 1 (GenBank accession No. NG021404); the transcription start site is located 22bp upstream of the ATG start codon [23] (Figure 3A). Substantial expression of MMP13 was detected in HFBCs samples $(354.2 \pm 254.2, \mathrm{n}=7$ ) (Figure 3B). Indeed, expression significantly correlated with femur length (Figure 3C). However, this significant increase in gene expression is not correlated with loss of methylation in any of the CpG sites inside the promoter (Figure 3D), in contrast to our observations for $i N O S$ and COL9A1.

Immunohistochemical analysis indicated that a considerable proportion of cells from fetal femurs produce MMP13 (Figure 3EI) with MMP13 expression noted to alter with the age of the sample. Thus in a younger tissue sample (from 7-8 WPG), MMP13 staining was typically weak and widespread in distribution across the tissue (Figure $3 \mathrm{E}-\mathrm{F}$ ). However, in older fetal samples (from 8.5-9 WPC), MMP13 staining was significantly stronger and observed to be predominantly distributed in the diaphysial centre, specifically in the distal part of the bone (Figure 3G-I).

\section{IL1B Gene Expression does not Correlate with Loss of Methylation during Fetal Femur Development}

No significant expression of $I L 1 B$ was detected in HFBCs compared with healthy adult chondrocytes (Figure 4A). The human $I L 1 B$ promoter (sparse CpG promoter) has $7 \mathrm{CpG}$ sites in the 900-bp sequence upstream of exon 1 and 1 CpG site within exon 1 (GenBank accession No. AY137079) (Figure 4B); the transcription start site was located $31 \mathrm{bp}$ downstream of a TATA box [24]. CpG sites within this proximal promoter region did not demonstrate a significant correlation between methylation levels and the size of the examined sample (Figure 4C). Interestingly at the CpG site located 299 base pairs upstream of the coding start site, a significant correlation between methylation levels and the size of the fetal femur sample was observed only in uncultured samples $(R=0.80)$. We have previously reported that this position is a crucial $\mathrm{CpG}$ site in the epigenetic induction of $I L 1 B$ in OA chondrocytes $[12,13]$.

Immunohistochemical analysis showed there was no significant expression of IL1B (Figure 4D-G). IL1B staining was only detectable in tissue samples from 7-8 WPC fetus, although IL1B staining was weak and observed to be distributed throughout the tissue (Figure 4D-E).

\section{Osteocalcin Promoter Region Methylation}

The human Osteocalcin promoter (sparse CpG promoter) has 10 CpG sites within the vitamin D response element [25]. Assessment of methylation status of this region in human embryonic stem cells (hESCs) revealed a hypermethylated state, 
consistent with a lack of osteocalcin expression (data not shown), and epigenetic silencing via methylation. Similarly, DNA isolated from fetal femur explants was hypermethylated at each CpG site investigated. Previously we have reported osteocalcin expression in HFBCs only when cells are incubated in osteogenic conditions [11]. However, at CpG sites 572, 559, 517 and 468 base pairs upstream of the osteocalcin start site, methylation was significantly lower for fetal femur DNA than hESC DNA (Figure 5A).

Significant demethylation was evident between the fetal and adult developmental stages. Methylation levels of CpG sites 572, $559,541,517,514,476,468,457$ and 422 base pairs upstream of the coding start site were statistically lower for uncultured $\mathrm{STRO}^{+}$ adult skeletal stem cells compared to HFBCs indicating demethylation at a developmental stage between fetal and adulthood. However, osteocalcin RNA expression was undetectable in $\mathrm{STRO}^{+}$adult skeletal stem cells indicating that demethylation occurs prior to induction of osteocalcin expression. In all instances, culture of $\mathrm{STRO}^{+}$adult skeletal stem cells resulted in further demethylation leading to a hypomethylated state regardless of osteocalcin expression (Figure 5A).

On examination of the $\mathrm{STRO}^{+}$and $\mathrm{STRO}^{-}$fractions, it was observed that three CpG sites (541, 517 and 514 base pairs upstream of the coding start site) displayed significantly greater methylation in $\mathrm{STRO}^{-}$cells (Figure 5B).

Immunohistochemical analysis demonstrated that a considerable proportion of cells from fetal femurs produce STRO-1 (Figure 5C-E). STRO-1 staining was typically weak in the proliferating chondrocyte population with localisation limited to the superficial area (Figure 5D); however, in the hypertrophic chondrocyte population, STRO-1 staining was significantly stronger (Figure 5E).

\section{Decreased DNMT1 Expression in Adult Chondrocytes}

qRT-PCR was used to determine whether decreased expression of DNMT1 contributed to the observed loss of DNA methylation in chondrocytes from adult cartilage. DNMT1 expression in healthy chondrocytes was observed to be almost half that of HFBCs (Figure 6). Additionally, DNMT1 expression in OA chondrocytes from the surface zone was less than half that observed in control chondrocytes from patients with femoral neck fracture (Figure 6), as it had been previously shown [13]. DNMT1 expression levels were found to be independent of fetal sample age $(\mathrm{R}=0.06)$.

\section{TET Proteins in Fetal Cells}

TET1-3 expression was analysed by qRT-PCR. However, only TET1 showed higher expression in HFBCs compared to human adult chondrocytes $(3.8 \pm 5.0$ versus $1.1 \pm 0.8 ; \mathrm{n}=9)$ (Figure $7 \mathrm{~A})$. However this difference was not statistically significant $(\mathrm{P}=0.15)$, and TET1 expression was observed to display a very weak correlation to fetal age (Figure 7B).

\section{Discussion}

Epigenetic marks, including $\mathrm{CpG}$ methylation, are generally stable in somatic cells; however, during at least two developmental time periods, the epigenome undergoes extensive epigenetic programming [26]. These critical windows of development include gametogenesis as well as early pre-implantation embryos [3]. The pattern of distribution of methyl groups in DNA differs depending on cell type and confers a cells specific identity on DNA during cellular differentiation and organogenesis. This is an innate and highly programmed process [27] and an understanding of the underlying epigenetic mechanisms that regulate gene expression in bone development provide important possibilities in tissue repair.

The human fetal femurs used in these studies contain predominantly epiphyseal chondrocytes surrounded by a perichondrium/periosteum consisting of an outer fibroblastic layer and an inner layer of non-committed mesenchymal stem cells, the latter capable of differentiating either along the chondrogenic, osteogenic or adipogenic lineages [11]. A first biological characterization of HFBCs has already been reported indicating that these cells have an enhanced capacity to proliferate compared with human osteoblasts and a higher capacity to differentiate in vitro into bone cells compared with mesenchymal cells [28]. Furthermore, other authors suggest that cells taken before 8 weeks of development represent a predominantly more primitive cell population [29]. To test the utility of HFBCs to study the epigenetic mechanisms implicated on bone development, we have examined the influence of DNA de-methylation on gene expression, with emphasis on physiological genes vital for bone biology (iNOS and COL9A1) and, catabolic/pathologic genes important for bone modulation and remodelling as well (MMP13 and IL1B). These genes, iNOS, COL9A1, MMP13 and $I L 1 B$ were selected as key genes linked to OA; in this regard we have already published on the importance of IL-1B and MMP13 in the context of cartilage and OA [12,13,14], and sought to extend these observations to our understanding during fetal development and the role of epigenetics. In all studies, human fetal femur derived skeletal cells were used directly after digestion as culture conditions alone can induce de-methylation.

iNOS plays an important role in various cell systems including bone, where it has a dual role. Evidence from gene-knockout studies indicates that bone formation and resorption are regulated by NO [30]. Furthermore, a number of studies have indicated the active involvement of $\mathrm{NO}$ in bone healing [31,32,33,34], bone development [35,36,37,38,39] and bone loss [40,41]. Thus tight regulation of $i N O S$ would be expected for this gene, and we observed such an exquisite epigenetic regulation of iNOS. The increase in expression levels correlated with loss of methylation in specific CpG sites localized at the transcription start site. Similarly, A2(1) collagen transcription is inhibited by methylation sites within the first exon at the initiation site of transcription [42]. Others have reported that effective gene suppression was observed when promoters were methylated in the pre-initiation domain [43]; methylation of coding regions are common in mammalian genes and reportedly improve genome stability [44]. In the context of bone, Delgado-Calle and collaborators have recently demonstrated that the methylation status of $\mathrm{CpG}$ dinucleotides within the proximal promoter plays an important role in the regulation of SOST (encodes Sclerostin protein) expression, impairing its expression in osteoblasts and other extraskeletal cells and permitting expression in osteocytes [45].

In HFBCs, in which we observed higher levels of methylation but no mRNA expression, inhibition of DNA methylation by 5aza-2'-deoxycytidine (5-aza) and trichostatin A (TSA) treatment, was not sufficient to induce iNOS expression; similar results were also recorded for adult chondrocytes (data not shown).

Type IX collagen, although a minority molecule in hyaline cartilage, is a key component acting as a molecular bridge between cartilage collagen fibrils and other matrix components, possibly proteoglycans $[46,47]$. It has been shown that the lack of collagen IX seriously affects growth plate organization, especially in young animals [48]; furthermore, COL9A1 deregulation is an accepted marker of OA [49]. Tight regulation is considered to occur during bone development and the current results are consistent with epigenetic control during fetal development. Critically a sequential 
loss of methylation was noted to correlate with an increase in gene expression. Further experiments were conducted and, after treatment with 5-aza plus TSA, COL9A1 expression correlated with DNA methylation (Imagawa et al., manuscript in preparation).

Bone development requires a complex remodelling of the extracellular matrix, and this is predominantly mediated by matrix metalloproteinases (MMPs) [30]. MMP13 is a potential target for NO regulation in bone development, with Cbfa-1 (RUNX2) a mediator of $\mathrm{NO}$ action [30]. We observed a spatial and sequential MMP13 expression, however this was independent of the methylation status of MMP13 promoter. Thus it would appear genes involved in normal femur development are epigenetically regulated during fetal femur development, however expression of catabolic genes such as MMP13 or IL1B are independent of DNA methylation. Nevertheless, previous experiments within our group showed interesting results in chondrocytes with 5-aza and TSA capable of inducing IL1B expression [13], and MMP13 (Hashimoto et al., manuscript in preparation); however, in HFBCs no changes in expression were detected for these genes (data not shown).

Furthermore, the reduction in DNMT1 expression levels observed in adult chondrocytes compared to HFBCs is in agreement with the increment of expression of certain vital genes for bone development.

Recently, it has been demonstrated that oxidation of 5methylcytosine to 5-hydroxymethylcytosine by TET family hydroxylases may also participate in active DNA demethylation [50,51]. Specifically, TET1 is involved in embryonic stem cell (ESC) maintenance and inner cell mass (ICM) cell specification, possibly by participating in DNA demethylation [52]. In this regard, we observed lower TET1 expression levels in adult chondrocytes in comparison to HFBCs samples, where an active de-methylation process is in progress. Conversion of 5-methylcytosine to 5-hydroxymethylcytosine may facilitate passive DNA demethylation by excluding the maintenance DNA methyltransferase DNMT1, which poorly recognizes 5-hydroxymethylcytosine [53]. Interestingly, it has been postulated that the balance between hydroxymetylation and methylation in the genome is inextricably linked with the balance between pluripotency and lineage commitment [54].

Osteocalcin is a non-collagenous protein secreted by osteoblasts and is therefore a specific marker for osteoblast activity [55]. Cells isolated from 12-14 WPC fetal femurs present characteristics of advanced osteoprogenitors compared with human mesenchymal stem cells isolated from bone marrow [29]. The $\mathrm{STRO}^{+}$fraction of adult bone marrow contains a population of skeletal stem cells with osteogenic, chondrogenic and adipogenic differentiation potential [17]. These cells are of potential interest for therapeutic use in bone tissue engineering. It has been reported that reduced DNA methylation of $\mathrm{CpG}$ islands in the osteocalcin and osteopontin genes is associated with osteogenic differentiation $[56,57]$. We did not detect osteocalcin expression but observed developmental stage-dependent demethylation suggesting that demethylation alone does not regulate osteocalcin expression but that methylation can prevent expression. However, the fact that certain CpG sites displayed significantly greater methylation in $\mathrm{STRO}^{-}$cells appears to be no coincidence given that the $\mathrm{STRO}^{+}$ fraction has osteogenic potential and thus the potential to express osteocalcin upon differentiation. Mirmalek-Sani and collaborators demonstrated that HFBCs expressed accelerated osteogenesis evidenced by reduced culture periods and higher levels of bone markers such as RUNX2, alkaline phosphatase (ALP) and COL1Al compared with human bone marrow derived mesen- chymal cells, suggesting that HFBCs are more advanced in their osteogenic program [11]. Montjovent and colleagues also reported enhanced ALP and mineralisation activity compared to adult mesenchymal populations [28]. Interestingly, HFBCs and HMSCs failed to express cartilage markers such as SOX9 and COL2A1. We have performed preliminary experiments using adult human osteosarcoma osteoblast-like bone cell lines (MG63 and Saos-2 unpublished observations). In these studies the human osteoblast like cell lines failed to express our genes of interest. Furthermore, the lack of expression was observed to correlate with high levels of methylation of most CpG sites of these promoters.

To date, there is a paucity of information regarding the role of DNA methylation in the differentiation of adult human skeletal cells, although some recent studies suggest that it is involved in the regulation of a number of bone genes, as well as in bone cell differentiation [56,58,59]. Previously, we have shown that monolayer cultures of human bone marrow stromal cells treated for 3 days with the 5-aza or TSA, followed by culture in the absence of modifiers displayed distinct phenotypic changes. 5-aza stimulated osteogenic differentiation (evidenced by enhanced ALP activity, increased Runx-2 expression in monolayer, and increased osteoid formation in 3D cell pellets) whilst pellet cultures of human skeletal cells in chondrogenic media with TSA enhanced cartilage matrix formation and chondrogenic structure [60].

Interestingly, it has recently been published that osteoblasts and osteocytes have opposite DNA methylation profiles in the $A L P$ promoter, which is hypomethylated in osteoblasts and hypermethylated in osteocytes, suggesting that DNA methylation is inhibiting $A L P$ expression in the latter [61].

In fetal bone femurs, relatively small numbers of differentiated osteoblasts were present along the central diaphysis, as indicated by the presence of the first bone collar. The cells that grew out from the dissected explants during culture could thus theoretically be derived from the cut edges of the epiphysis (early chondrocytes) or from the perichondrium (fibroblastic or mesenchymal stem cells). Given epiphyseal chondrocytes were by far the most frequent cell type present in the fetal femurs and as most outgrowth was observed from the cut edges, it is probable that the starting cells were early chondroprogenitor and mesenchymal progenitor populations [11]. Recent experiments in our group analysed DNA methylation status of genes over- or underexpressed in a sub-set of samples. These studies found that $100 \%$ of over-expressing samples but just $43 \%$ of under-expressing samples had decreased promoter methylation [62].

\section{Conclusions}

Here we show that the regulation of genes involved during normal bone development are controlled by epigenetic mechanisms, specifically loss of methylation in crucial CpG sites of their proximal promoters. In conclusion, these findings demonstrate the role of epigenetic regulation, specifically DNA methylation, in bone development, informing and opening new possibilities in development of strategies for bone repair and tissue engineering.

\section{Acknowledgments}

The authors thank the Orthopaedic Surgeons at Southampton General Hospital for provision of femoral heads from patients undergoing total hip replacement surgery. We are also grateful for the help of Anne Chad, staff and patients in providing access to fetal tissues, and Kelvin S. C. Cheung for STRO-1 immunostaining. 


\section{Author Contributions}

Conceived and designed the experiments: RO HIR MCA EK. Performed the experiments: MCA EK KI. Analyzed the data: MCA EK KI AG DIW

\section{References}

1. Reik W, Walter J (2001) Genomic imprinting: parental influence on the genome. Nat Rev Genet 2: 21-32.

2. Robertson KD (2005) DNA methylation and human disease. Nat Rev Genet 6: 597-610.

3. Reik W, Dean W, Walter J (2001) Epigenetic reprogramming in mammalian development. Science 293: 1089-1093.

4. Cheng X (1995) Structure and function of DNA methyltransferases. Annu Rev Biophys Biomol Struct 24: 293-318.

5. Godfrey KM, Lillycrop KA, Burdge GC, Gluckman PD, Hanson MA (2007) Epigenetic mechanisms and the mismatch concept of the developmental origins of health and disease. Pediatr Res 61: 5R-10R.

6. Vickaryous N, Whitelaw E (2005) The role of early embryonic environment on epigenotype and phenotype. Reprod Fertil Dev 17: 335-340.

7. Bird A (2002) DNA methylation patterns and epigenetic memory. Genes Dev 16: 6-21.

8. Jackson-Grusby L, Beard C, Possemato R, Tudor M, Fambrough D, et al. (2001) Loss of genomic methylation causes p53-dependent apoptosis and epigenetic deregulation. Nat Genet 27: 31-39.

9. Pfeifer GP, Steigerwald SD, Hansen RS, Gartler SM, Riggs AD (1990) Polymerase chain reaction-aided genomic sequencing of an X chromosomelinked $\mathrm{CpG}$ island: methylation patterns suggest clonal inheritance, CpG site autonomy, and an explanation of activity state stability. Proc Natl Acad Sci U S A 87: 8252-8256.

10. Reik W, Walter J (2001) Evolution of imprinting mechanisms: the battle of the sexes begins in the zygote. Nat Genet 27: 255-256.

11. Mirmalek-Sani SH, Tare RS, Morgan SM, Roach HI, Wilson DI, et al. (2006) Characterization and multipotentiality of human fetal femur-derived cells: implications for skeletal tissue regeneration. Stem Cells 24: 1042-1053.

12. Imagawa K, de Andres MC, Hashimoto K, Pitt D, Itoi E, et al. (2011) The epigenetic effect of glucosamine and a nuclear factor-kappa $\mathrm{B}(\mathrm{NF}-\mathrm{kB})$ inhibitor on primary human chondrocytes-implications for osteoarthritis. Biochem Biophys Res Commun 405: 362-367.

13. Hashimoto K, Oreffo RO, Gibson MB, Goldring MB, Roach HI (2009) DNA demethylation at specific CpG sites in the IL1B promoter in response to inflammatory cytokines in human articular chondrocytes. Arthritis Rheum 60: 3303-3313.

14. Roach HI, Yamada N, Cheung KS, Tilley S, Clarke NM, et al. (2005) Association between the abnormal expression of matrix-degrading enzymes by human osteoarthritic chondrocytes and demethylation of specific CpG sites in the promoter regions. Arthritis Rheum 52: 3110-3124.

15. da Silva MA, Yamada N, Clarke NM, Roach HI (2009) Cellular and epigenetic features of a young healthy and a young osteoarthritic cartilage compared with aged control and OA cartilage. J Orthop Res 27: 593-601.

16. Stewart K, Monk P, Walsh S, Jefferiss CM, Letchford J, et al. (2003) STRO-1, HOP-26 (CD63), CD49a and SB-10 (CD166) as markers of primitive human marrow stromal cells and their more differentiated progeny: a comparative investigation in vitro. Cell Tissue Res 313: 281-290.

17. Gronthos S, Graves SE, Ohta S, Simmons PJ (1994) The STRO-1+ fraction of adult human bone marrow contains the osteogenic precursors. Blood 84: 4164 4173 .

18. Stewart K, Walsh S, Screen J, Jefferiss CM, Chainey J, et al. (1999) Further characterization of cells expressing STRO-1 in cultures of adult human bone marrow stromal cells. J Bone Miner Res 14: 1345-1356.

19. Hashimoto K, Kokubun S, Itoi E, Roach HI (2007) Improved quantification of DNA methylation using methylation-sensitive restriction enzymes and real-time PCR. Epigenetics 2: 86-91.

20. Chartrain NA, Geller DA, Koty PP, Sitrin NF, Nussler AK, et al. (1994) Molecular cloning, structure, and chromosomal localization of the human inducible nitric oxide synthase gene. J Biol Chem 269: 6765-6772.

21. Palmer RM, Hickery MS, Charles IG, Moncada S, Bayliss MT (1993) Induction of nitric oxide synthase in human chondrocytes. Biochem Biophys Res Commun 193: 398-405.

22. Zhang P, Jimenez SA, Stokes DG (2003) Regulation of human COL9A1 gene expression. Activation of the proximal promoter region by SOX9. J Biol Chem 278: 117-123.

23. Tardif G, Pelletier JP, Dupuis M, Hambor JE, Martel-Pelletier J (1997) Cloning, sequencing and characterization of the $5^{\prime}$-flanking region of the human collagenase-3 gene. Biochem J 323 (Pt 1): 13-16.

24. Clark BD, Collins KL, Gandy MS, Webb AC, Auron PE (1986) Genomic sequence for human prointerleukin 1 beta: possible evolution from a reverse transcribed prointerleukin 1 alpha gene. Nucleic Acids Res 14: 7897-7914.

25. Kerner SA, Scott RA, Pike JW (1989) Sequence elements in the human osteocalcin gene confer basal activation and inducible response to hormonal vitamin D3. Proc Natl Acad Sci U S A 86: 4455-4459.

26. Dolinoy DC, Weidman JR, Jirtle RL (2007) Epigenetic gene regulation: linking early developmental environment to adult disease. Reprod Toxicol 23: 297-307.
RO. Contributed reagents/materials/analysis tools: HIR RO. Wrote the paper: MCA EK AG DIW RO.

27. Szyf M (2011) The early life social environment and DNA methylation: DNA methylation mediating the long-term impact of social environments early in life. Epigenetics 6: 971-978.

28. Montjovent MO, Burri N, Mark S, Federici E, Scaletta C, et al. (2004) Fetal bone cells for tissue engineering. Bone 35: 1323-1333.

29. Krattinger N, Applegate LA, Biver E, Pioletti DP, Caverzasio J (2011) Regulation of proliferation and differentiation of human fetal bone cells. Eur Cell Mater 21: 46-58.

30. Zaragoza C, Lopez-Rivera E, Garcia-Rama C, Saura M, Martinez-Ruiz A, et al. (2006) Cbfa-1 mediates nitric oxide regulation of MMP-13 in osteoblasts. J Cell Sci 119: 1896-1902.

31. Corbett SA, Hukkanen M, Batten J, McCarthy ID, Polak JM, et al. (1999) Nitric oxide in fracture repair. Differential localisation, expression and activity of nitric oxide synthases. J Bone Joint Surg Br 81: 531-537.

32. Diwan AD, Wang MX, Jang D, Zhu W, Murrell GA (2000) Nitric oxide modulates fracture healing. J Bone Miner Res 15: 342-351.

33. Wang FS, Kuo YR, Wang CJ, Yang KD, Chang PR, et al. (2004) Nitric oxide mediates ultrasound-induced hypoxia-inducible factor-1alpha activation and vascular endothelial growth factor-A expression in human osteoblasts. Bone 35: $114-123$.

34. Zhu W, Diwan AD, Lin JH, Murrell GA (2001) Nitric oxide synthase isoforms during fracture healing. J Bone Miner Res 16: 535-540.

35. Aguirre J, Buttery L, O'Shaughnessy M, Afzal F, Fernandez de Marticorena I, et al. (2001) Endothelial nitric oxide synthase gene-deficient mice demonstrate marked retardation in postnatal bone formation, reduced bone volume, and defects in osteoblast maturation and activity. Am J Pathol 158: 247-257.

36. Armour KE, Armour KJ, Gallagher ME, Godecke A, Helfrich MH, et al. (2001) Defective bone formation and anabolic response to exogenous estrogen in mice with targeted disruption of endothelial nitric oxide synthase. Endocrinology 142: 760-766.

37. Collin-Osdoby P, Nickols GA, Osdoby P (1995) Bone cell function, regulation, and communication: a role for nitric oxide. J Cell Biochem 57: 399-408.

38. Turner CH, Owan I, Jacob DS, McGlintock R, Peacock M (1997) Effects of nitric oxide synthase inhibitors on bone formation in rats. Bone 21: 487-490.

39. van't Hof RJ, Ralston SH (2001) Nitric oxide and bone. Immunology 103: 255261.

40. Cuzzocrea S, Mazzon E, Dugo L, Genovese T, Di Paola R, et al. (2003) Inducible nitric oxide synthase mediates bone loss in ovariectomized mice. Endocrinology 144: 1098-1107.

41. Wang FS, Wang CJ, Chen YJ, Huang YT, Huang HC, et al. (2004) Nitric oxide donor increases osteoprotegerin production and osteoclastogenesis inhibitory activity in bone marrow stromal cells from ovariectomized rats. Endocrinology 145: 2148-2156.

42. Sengupta PK, Smith BD (1998) Methylation in the initiation region of the first exon suppresses collagen pro-alpha2(I) gene transcription. Biochim Biophys Acta 1443: 75-89.

43. Levine A, Cantoni GL, Razin A (1992) Methylation in the preinitiation domain suppresses gene transcription by an indirect mechanism. Proc Natl Acad Sci U S A 89: $10119-10123$

44. Weber M, Schubeler D (2007) Genomic patterns of DNA methylation: targets and function of an epigenetic mark. Curr Opin Cell Biol 19: 273-280.

45. Delgado-Calle J, Sanudo C, Bolado A, Fernandez AF, Arozamena J, et al. (2012) DNA methylation contributes to the regulation of sclerostin expression in human osteocytes. J Bone Miner Res 27: 926-937.

46. Hagg R, Hedbom E, Mollers U, Aszodi A, Fassler R, et al. (1997) Absence of the alphal(IX) chain leads to a functional knock-out of the entire collagen IX protein in mice. J Biol Chem 272: 20650-20654.

47. Fassler R, Schnegelsberg PN, Dausman J, Shinya T, Muragaki Y, et al. (1994) Mice lacking alpha 1 (IX) collagen develop noninflammatory degenerative joint disease. Proc Natl Acad Sci U S A 91: 5070-5074.

48. Dreier R, Opolka A, Grifka J, Bruckner P, Grassel S (2008) Collagen IXdeficiency seriously compromises growth cartilage development in mice. Matrix Biol 27: 319-329.

49. Alizadeh BZ, Njajou OT, Bijkerk C, Meulenbelt I, Wildt SC, et al. (2005) Evidence for a role of the genomic region of the gene encoding for the alphal chain of type IX collagen (COL9A1) in hip osteoarthritis: A population-based study. Arthritis Rheum 52: 1437-1442.

50. Kriaucionis S, Heintz N (2009) The nuclear DNA base 5-hydroxymethylcytosine is present in Purkinje neurons and the brain. Science 324: 929-930.

51. Tahiliani M, Koh KP, Shen Y, Pastor WA, Bandukwala H, et al. (2009) Conversion of 5-methylcytosine to 5-hydroxymethylcytosine in mammalian DNA by MLL partner TET1. Science 324: 930-935.

52. Ito S, D'Alessio AC, Taranova OV, Hong K, Sowers LC, et al. (2010) Role of Tet proteins in $5 \mathrm{mC}$ to $5 \mathrm{hmC}$ conversion, ES-cell self-renewal and inner cell mass specification. Nature 466: 1129-1133. 
53. Valinluck V, Sowers LC (2007) Endogenous cytosine damage products alter the site selectivity of human DNA maintenance methyltransferase DNMT1. Cancer Res 67: 946-950.

54. Ficz G, Branco MR, Seisenberger S, Santos F, Krueger F, et al. (2011) Dynamic regulation of 5-hydroxymethylcytosine in mouse ES cells and during differentiation. Nature 473: 398-402.

55. Brown JP, Delmas PD, Malaval L, Edouard C, Chapuy MC, et al. (1984) Serum bone Gla-protein: a specific marker for bone formation in postmenopausal osteoporosis. Lancet 1: 1091-1093.

56. Arnsdorf EJ, Tummala P, Castillo AB, Zhang F, Jacobs CR (2010) The epigenetic mechanism of mechanically induced osteogenic differentiation. J Biomech 43: 2881-2886.

57. Villagra A, Gutierrez J, Paredes R, Sierra J, Puchi M, et al. (2002) Reduced CpG methylation is associated with transcriptional activation of the bone-specific rat osteocalcin gene in osteoblasts. J Cell Biochem 85: 112-122.
58. Kitazawa R, Kitazawa S (2007) Methylation status of a single CpG locus 3 bases upstream of TATA-box of receptor activator of nuclear factor-kappaB ligand (RANKL) gene promoter modulates cell- and tissue-specific RANKL expression and osteoclastogenesis. Mol Endocrinol 21: 148-158.

59. Lu TY, Kao CF, Lin CT, Huang DY, Chiu CY, et al. (2009) DNA methylation and histone modification regulate silencing of OPG during tumor progression. J Cell Biochem 108: 315-325.

60. El-Serafi AT, Oreffo RO, Roach HI (2011) Epigenetic modifiers influence lineage commitment of human bone marrow stromal cells: Differential effects of 5-aza-deoxycytidine and trichostatin A. Differentiation 81: 35-41.

61. Delgado-Calle J, Sanudo C, Sanchez-Verde L, Garcia-Renedo RJ, Arozamena J, et al. (2011) Epigenetic regulation of alkaline phosphatase in human cells of the osteoblastic lineage. Bone 49: 830-838.

62. Lanham SA, Bertram G, Cooper C, Oreffo RO (2011) Animal models of maternal nutrition and altered offspring bone structure-bone development across the lifecourse. Eur Cell Mater 22: 321-332; discussion 332. 